\title{
HUBUNGAN DUKUNGAN KELUARGA DENGAN KEIKUTSERTAAN KELAS IBU HAMIL DI KLINIK BIDAN WANTI
}

\author{
Lasma Rina Efrina Sinurat ${ }^{1}$, Rosetty Rita Sipayung ${ }^{2}$, \\ Yunida Turisma Oktavia Simanjuntak ${ }^{3}$ \\ ${ }_{1,2,3}$ Univrsitas Sari Mutiara Indonesia, Medan \\ Email: lasma.rina.sinurat13@gmail.com ${ }^{1}$, rosetty.sipayung@gmail.com² \\ yunidastak15@gmail.com ${ }^{3}$
}

\begin{abstract}
Abstrak
Kelas ibu hamil merupakan usaha untuk menurunkan laju angka kematian ibu dengan meningkatkan pengetahuan, keterampilan ibu hamil mengenai kehamilan, persalinan dan nifas. Dukungan keluarga diperkirakan berpotensi mempengaruhi keikutsertaan ibu dalam kelas ibu hamil. Support sistem dari keluarga yang diberikan melalui perhatian, bantuan baik materi maupun moril yang diberikan oleh suatu kelompok atau individu lain, khususnya yaitu dukungan dari suami. Tujuan penelitian ini untuk mengetahui hubungan dukungan keluarga dengan keikutsertaan kelas ibu hamil. Metode yang digunakan adalah penelitian analitik korelasi dengan studi cross-sectional, dengan tehnik pengambilan sampel menggunakan teknik total sampling sehingga didapatkan jumlah sampel 32 orang ibu hamil. Hasilnya menunjukkan bahwa dukungan keluarga pada ibu hamil mayoritas mendukung $(59,4 \%)$ dan keikutsertaan ibu hamil mayoritas mengikuti kelas ibu hamil $(53,1 \%)$ di Klinik Bidan Wanti. Hasil uji statistik menunjukkan ada hubungan yang signifikan antara dukungan keluarga dengan keikutsertaan kelas ibu hamil di Klinik Bidan Wanti, dengan nilai $p$ value $0,005(\alpha<0,05)$. Disimpulkan bahwa semakin baik dukungan keluarga terkhusus suami dan aktif mengikuti kelas hamil maka akan mengurangi kematian pada ibu.
\end{abstract}

Kata Kunci : Dukungan keluarga, kelas ibu hamil, ibu hamil

\begin{abstract}
The class for pregnant women is an attempt to reduce the rate of maternal mortality by increasing the knowledge and skills of pregnant women regarding pregnancy, childbirth and the postpartum period. Family support is estimated to have the potential to affect the participation of mothers in the class of pregnant women. The support system from the family is given through attention, both material and moral assistance provided by a group or other individual, especially the support from the husband. The purpose of this study was to determine the relationship between family support and class participation of pregnant women. The method used is a correlation analytic study with a cross-sectional study, with a sampling technique using a total sampling technique so that a total sample of 32 pregnant women is obtained. The results show that the majority of family support for pregnant women supports $(59.4 \%)$ and the majority of pregnant women participate in pregnant women's classes $(53.1 \%)$ at the Wanti Midwife Clinic. The results of statistical tests showed that there was a significant relationship between family support and class participation of pregnant women at the Wanti Clinic, with a $p$ value of $0.005(\alpha<0.05)$. It was concluded that the better the family support, especially the husband and active participation in pregnancy classes, the less maternal mortality.
\end{abstract}




\section{Kata Kunci: Family support, class of pregnant}

\section{PENDAHULUAN}

Proses kehamilan sampai persalinan merupakan pengalaman yang sangat berharga bagi seorang wanita karena pada masa ini adalah masa meningkatnya kewaspadaan dan terjadinya perubahan besar baik pada ibu hamil tersebut maupun pada keluarga terutama suami. Namun tidak semua wanita mengalami kehamilan yang lancar dan diakhiri dengan persalinan yang aman sehingga ibu dapat melahirkan bayinya dalam keadaan sehat. Pengobatan yang dimulai selama kehamilan akan membantu menurunkan Angka Kematian Ibu (AKI) Indonesia yang mencapai 228 per 100.000 (Kemenkes RI, 2013).

Angka Kematian Bayi (AKB) dan AKI merupakan indikator penting dari derajat kesehatan masyarakat dan keberhasilan pelayanan kesehatan serta masalah kesehatan di seluruh negara. AKI di dunia pada tahun 2015 diperkirakan World Health Organization (WHO) mencapai 297.000 jiwa dan penyumbang terbesar berasal dari negara berkembang yang mencapai 99\% (294 000 jiwa) (WHO, 2015).

Berdasarkan hasil survei Demografi dan Kesehatan Indonesia (SDKI) AKI mengalami peningkatan dari tahun 2010 sampai dengan tahun 2015. Sementara itu menurut data Dinas Kesehatan Provinsi Sumatra Utara AKI mengalami penurunan dari 158 per 100.000 kelahiran hidup (KH) tahun 2014 menjadi 145 per KH tahun 2015 namun hasil tersebut masih sangat jauh dari target MDG's tahun 2015102 per $100.000 \mathrm{KH}$ (Masini, 2015).

Mengingat masih tingginya AKI, pemerintah melalui Kementerian Kesehatan telah merumuskan kebijakan untuk menurunkan angka kematian ibu. Pelayanan Antenatal Care (ANC) yang dilaksanakan oleh tenaga kesehatan selama kehamilan sebagai pencegahan dini terhadap faktor risiko yang terjadi selama kehamilan (Wittmann-Price et al., 2019). Menurut Mariana, et.al., (2018) selama operasionalnya, setiap ibu hamil yang berkunjung ke kegiatan ANC akan mendapatkan buku KIA. Didesain agar ibu dapat membaca "Buku Panduan Kesehatan Ibu dan Anak" berulang kali di rumah, sehingga ibu dapat memahami kondisi yang dialaminya selama masa kehamilan, persalinan, nifas, dan neonatus. Namun kenyataannya tidak semua ibu mau membaca buku ini. Ada banyak alasan. Ada ibu yang tidak sempat membaca, atau terlalu malas untuk membaca buku KIA. Mereka kesulitan memahami isi buku KIA, dan ada juga ibu-ibu yang tidak bisa membaca.

Oleh karena itu, ibu hamil perlu diajarkan untuk memahami isi buku KIA dan cara penggunaan buku tersebut. Salah satu solusinya adalah dengan mengadakan kelas untuk ibu hamil. Kelas Bersalin merupakan kelompok kelas belajar untuk ibu hamil yang usia kehamilannya antara 20 dan 36 minggu, dengan jumlah peserta maksimal 10 orang. Kelas ini akan belajar tentang kesehatan ibu hamil secara tatap muka kelompok, bertujuan untuk meningkatkan pengetahuan dan keterampilan ibu hamil dalam kehamilan, nifas, nifas, bayi baru lahir, penyakit menular, dll, tentang HIV/AIDS dan mitos (Kementrian Kesehatan RI, 2020). 
Menurut data dari Dinas Kesehatan Provinsi Sumatra Utara tahun 2015 dari 12 kabupaten/kota, kota Medan memiliki jumlah ibu hamil terbanyak kedua yaitu sebesar 27.358 orang. Hasil survey penelitian yang dilakukan Yusmaharani pada seluruh puskesmas yang ada di kota Medan dan 5 Klinik didapatkan dari 41 puskesmas dan 5 Klinik yang ada di Medan terdapat $89(3,7 \%)$ kelas ibu hamil yang dilaksanakan pada tahun 2015, ini jauh dari jumlah ideal kelas ibu hamil dimana total ibu hamil di Medan sebanyak 27.358 orang ibu hamil yang seharusnya adalah 2.380 kelas atau setidaknya $80 \%$ kelas ibu hamil terbentuk yaitu sebanyak 1904 kelas yang ikuti oleh 10 orang ibu hamil (Prabhakara, 2010).

Menurut Juliani tahun 2018 ada beberapa faktor penyebab ibu tidak mengikuti salah satu kursus untuk ibu hamil adalah dukungan keluarga. Bentuk dukungan keluargai ada 4 yaitu dukungan instrumental misalnya tidak bisa mengantarkan ke klinik yang dikarenakan jadwal kelas ibu hamil bersamaan dengan jam kerja keluarga, ini dapat disebabkan karena keluarga sudah pergi kerja dan keluarga mengangap ibu mampu mampu untuk sendiri, dukungan informasi : keluarga kurang mengetahui manfaat kelas ibu hamil, sehingga keluarga tidak begitu mendukung ibu hamil untuk ikut senam hamil, dukungan emosional : keluarga mengaggap bahwa ibu hamil bisa mandiri dalam kegiatan kelas ibu hamil, dukungan penilaian : keluarga tidak pernah memuji ibu hamil selama mengikuti senam hamil (Astuti et al., 2016)

Keterlibatan keluarga sejak awal masa kehamilan akan mempermudah dan meringankan ibu dalam menjalani dan mengatasi berbagai perubahan yang terjadi pada tubuh ibu akibat hadirnya janin di dalam perut. Sejalan dengan program ini diharapkan minimal satu kali pertemuan ibu hamil didampingi keluarga. Dikarenakan orang yang paling penting bagi seorang ibu hamil adalah keluarga. Bukti yang ditunjukkan bahwa ibu hamil yang diperhatikan dan dikasihi oleh keluarganya selama kehamilan akan menunjukan lebih sedikit gejala emosi dan fisik, lebih mudah melakukan penyesuaian diri selama kehamilan dan sedikit resiko komplikasi persalinan. Hal ini diyakini karena ada dua kebutuhan utama yang ditunjukan ibu selama hamil yaitu menerima tanda- tanda bahwa dicintai dan dihargai serta kebutuhan akan penerimaan pasangan terhadap anaknya (Prabhakara, 2010)

Hasil penelitian Masini (2015) tentang partisipasi ibu, didapatkan ibu yang berpartisipasi kurang mendapatkan dukungan keluarga dengan kategori kurang mendukung yaitu 63,6\% dibanding ibu yang mendapatkan dukungan keluarga dengan kategori mendukung 36,4\%. Sedangkan ibu yang berpartisipasi aktif dalam kelas ibu hamil, lebih banyak pada ibu yang mendapatkan dukungan keluarga dengan kategori mendukung sebesar 60,7\% dibanding ibu yang mendapatkan dukungan keluarga dengan kategori kurang mendukung.

Berdasarkan hasil studi pendahuluan yang dilakukan di Klinik Bidan Wanti didapatkan rendahnya keikutsertaan Kelas ibu hamil tergambarkan dalam setiap pelaksanaan kelas ibu hamil dihadiri rata-rata hanya 5-6 orang setiap bulannya sedangkan rata-rata jumlah ibu hamil di satu kelurahan mencapai 40 orang ibu hamil. Hal ini menandakan pemanfaatan kelas ibu hamil yang belum maksimal. Padahal kehadiran dalam kelas ibu hamil sangat penting dalam meningkatkan pengetahuan, mengubah sikap dan prilaku ibu agar memahami tentang kehamilan, persalinan, nifas, KB pasca persalinan termasuk perawatan bayi baru lahir. 


\section{Metode}

Desain pada penelitian ini adalah analitik korelasi dengan studi cross-sectional. Dalam penelitian ini yang menjadi populasi adalah seluruh ibu hamil yang datang ke Klinik Bidan Wanti untuk kontrol kehamilan pada bulan Juni dengan usia kehamilan maksimal 9 bulan yang berjumlah 32 orang. Pemilihan sampel menggunakan tehnik total sampling. Berdasarkan hal tersebut, jumlah sampel pada penelitian ini berjumlah 32 orang. Adapun untuk mengukur dukungan keluarga pada ibu hamil peneliti menggunakan self-report berupa kuesioner dengan nilai realibility 0,84 (Cronbach's Alpha) dengan total 45 pernyataan yang terbagi menjadi 4 kategori, pada pernyataan positif $(1,2,4,5,6,7,8,9,10,12,13,14,15,16,20,21,22,23,24,25,26,27,28,29,30,31,32,33,34,35,37,8$, $39,40,41,42,43,44,45)$ yaitu Selalu=4; Sering=3; Jarang=2; Tidak Pernah=1, sedangkan pada pernyataan negatif $(3,11,17,18,19,36)$ penilainnya adalah Selalu=1; Sering=2; Jarang=3; Tidak Pernah $=4$. Analisa data secara statistik dilakukan dengan menggunakan uji statistik Chi-square dengan $\alpha<0,05$ dan CI 95\%.

\section{Hasil Penelitian}

1. Karakteristik Ibu Hamil

Tabel 4.1

Distribusi Frekuensi Karakteristik Karakteristik ibu hamil di Klinik Bidan Wanti $(\mathrm{n}=32)$

\begin{tabular}{|c|c|c|}
\hline Karakteristik & $\mathrm{n}$ & $\%$ \\
\hline Usia & & \\
\hline 18-35 Tahun & 19 & 59.4 \\
\hline 36-55 Tahun & 13 & 40.6 \\
\hline \multicolumn{3}{|l|}{ Pendidikan } \\
\hline SMP & 7 & 21.9 \\
\hline SMA & 18 & 56.3 \\
\hline Diploma/Sarjana & 7 & 21.9 \\
\hline \multicolumn{3}{|l|}{ Usia Kehamilan } \\
\hline$<20$ Minggu & 9 & 28.1 \\
\hline 20-37 Minggu & 17 & 53.1 \\
\hline 38-42 Minggu & 6 & 18.8 \\
\hline
\end{tabular}

Berdasarkan tabel 4.1, didapatakan karakteristik ibu hamil berdasarkan data demografi di Klinik Bidan Wanti mayoritas berusia 18-35 tahun $(59,4 \%)$, pendidikan SMA $(56,3 \%)$ dan usia kehamilan 20-37 minggu (53,1\%).

2. Dukungan Keluarga

Tabel 4.2 
Distribusi Frekuensi Dukungan Keluarga Pada Ibu Hamil

Di Klinik Bidan Wanti $(\mathrm{n}=32)$

\begin{tabular}{lcc}
\hline \multicolumn{1}{c}{ Dukungan Keluarga } & $\mathrm{n}$ & $\%$ \\
\hline Mendukung & 19 & 59.4 \\
Tidak Mendukung & 13 & 40.6 \\
\hline
\end{tabular}

Berdasarkan tabel 4.2, didapatkan dukungan keluarga pada ibu hamil di Klinik Bidan Wanti mayoritas mendukung $(59,4 \%)$.

3. Keikutsertaan Kelas Ibu Hamil

Tabel 4.3

Distribusi Frekuensi Keikutsertaan Kelas Ibu Hamil Di Klinik Bidan Wanti (n=32)

\begin{tabular}{lccc}
\hline & Keikutsertaan Kelas Ibu Hamil & $\mathrm{n}$ & $\%$ \\
\hline Ya & 17 & 53.1 \\
Tidak & 15 & 46.9 \\
\hline
\end{tabular}

Berdasarkan tabel 4.3, didapatkan keikutsertaan ibu hamil di Klinik Bidan Wanti mayoritas mengikuti kelas ibu hamil $(53,1 \%)$.

4. Hubungan Dukungan Keluarga Dengan Keikutsertaan Kelas Ibu Hamil Di Klinik Bidan Wanti

Tabel 4.4

Hubungan Dukungan Keluarga Dengan Keikutsertaan Kelas Ibu Hamil Di Klinik Bidan Wanti $(\mathrm{n}=32)$

\begin{tabular}{lcccccccc}
\hline \multirow{2}{*}{ Dukungan Keluarga } & \multicolumn{4}{c}{ Keikutsertaan } & \multicolumn{2}{c}{ Total } & $p$ \\
\cline { 2 - 8 } & \multicolumn{3}{c}{ Ya } & \multicolumn{4}{c}{ Tidak } & \multicolumn{2}{c}{$p$} \\
\cline { 2 - 7 } & $\mathrm{n}$ & $\%$ & $\mathrm{n}$ & $\%$ & $\mathrm{n}$ & $\%$ & \\
\hline Mendukung & 14 & 43.8 & 5 & 15.6 & 19 & 59.4 & 0.00 \\
\hline Tidak mendukung & 3 & 9.4 & 10 & 31.3 & 13 & 40.6 & 5 \\
\hline Total & 17 & 53.1 & 15 & 46.9 & 32 & 100.0 & \\
\hline
\end{tabular}

Berdasarkan tabel 4.4, didapatkan dari 59,4\% ibu hamil yang didukung keluarga untuk mengikuti kelas ibu hamil mayoritas ikut serta dalam kelas ibu hamil, dan 40,6\% ibu hamil yang tidak didukung oleh keluarga untuk ikut serta dalam kelas ibu hamil mayoritas tidak mengikuti kelas ibu hamil. Hasil uji statistik diperoleh nilai $p$ value 0,005 $(\alpha<0,05)$, yang berarti ada hubungan yang signifikan antara dukungan keluarga dengan keikutsertaan kelas ibu hamil di Klinik Bidan Wanti.

\section{Pembahasan}

1. Dukungan Keluarga

Berdasarkan hasil penelitian didapatkan dukungan keluarga pada ibu hamil di Klinik Bidan Wanti mayoritas mendukung (59,4\%). Sejalan dengan hasil penelitian Yusmaharani, et.al., (2019) menunjukkan bahwa dari 211 ibu trimester III didapatkan hasil bahwa ibu hamil yang tidak didukung oleh suami sebanyak 99 orang $(46,9 \%)$ dan yang didukung oleh suaminya sebanyak 112 orang $(53,1 \%)$ 
Dukungan keluarga yang ditunjukkan memberikan efek yang bermanfaat bagi kesehatan fisik dan mental pada wanita hamil. Oleh karna itu, dukungan keluarga sangat memiliki andil yang besar dalam menentukan status kesehatan ibu. Jika anggota keluarga menginginkan kehamilan, mendukung, bahkan memperlihatkan dukungannya dalam berbagai hal maka ibu hamil akan merasa lebih percaya diri, lebih bahagia, dan siap dalam menjalani kehamilan, persalinan dan masa nifas (Sawan \& Buleleng, 2019). Dukungan sosial meliputi dukungan emosional adalah meliputi rasa cinta dan keyakinan dukungan informasional adalah dukungan dalam bentuk informasi dalam memberikan jalan keluar untuk memecahkan masalah, dukungan instrumental dapat diberikan dengan menyediakan sarana prasarana, peluang kesempatan dan waktu, dan dukungan appraisal adalah dukungan berupa pemberian pujian dan umpan balik mengenai hasil atau prestasi yang diraih (Tarigan, 2013).

Adanya dukungan dari keluarga berpengaruh besar dalam memastikan status kesehatan ibu. Keterlibatan anggota keluarga atau orang terdekat terutama pasangan/suami dapat memberikan kontribusi terhadap perubahan untuk berkarakter dan juga menambah pengetahuan dan pemahaman untuk beralih ke arah hidup sehat. Apabila dilihat dari informasi kesehatan lebih banyak diperoleh dari petugas kesehatan, keluarga dan masyarakat, namun pada bentuk-bentuk dukungan sosial lainnya suamilah yang paling berperan (Uktutias et al., 2018).

Pentingnya peran keluarga terutama suami pada ibu hamil tidak hanya sebagai pengambil keputusan, keluarga juga diharapkan selalu siaga dan selalu memberi perhatian terhadap kesehatan dan keselamatan ibu hamil. Dukungan keluarga sangat mendukung dalam pembentukan perilaku kesehatan ibu karena ibu hamil akan mengara pada apa yang disarankan oleh keluarga terutama suaminya, sehingga dorongan sosial keluarga menjadi faktor yang besar hubungannya dengan keikutsertaan ibu dalam mengikuti kegiatan apapun (Syam et al., 2018).

Support pada keluarga juga merupakan satu faktor penguat (reinforcing factor) yang dapat mempengaruhi seseorang dalam berperilaku. Dukungan pasangan akan meningkatkan kesiapan ibu hamil dalam menghadapi kehamilannya, dan proses persalinan hingga ke persiapan menjadi orang tua. Keterlibatan keluarga sejak awal masa kehamilan akan mempermudah dan meringankan ibu dalam menjalani kehamilannya. Sejalan dengan program ini diharapkan minimal satukali pertemuan ibu hamil didampingi suami/keluarga. Hal ini dimaksudkan agar kesehatan ibu selama hamil, bersalin, nifas, termasuk kesehatan bayi yang baru dilahirkannya dan kebutuhan akan KB pasca persalinan menjadi perhatian dan tanggung jawab seluruh keluarga (Kholid, 2012).

\section{Keikutsertaan Kelas Ibu Hamil Di Klinik Bidan Wanti}

Hasil penelitian menunjukkan bahwa keikutsertaan ibu dalam kelas ibu hamil di Klinik Bidan Wanti rata-rata 5 kali selama kehamilan. Hasil penelitian menunjukkan bahwa ibu yang berpartisipasi dalam kelas ibu hamil antara yang berpartisipasi aktif dan yang berpartisipasi kurang mempunyai presentase hampir sama. Dikatakan berpartisipasi aktif dalam kelas ibu hamil apabila frekuensi ikutserta dalam kelas ibu hamil $\geq 3$ kali selama kehamilannya. Dari hasil penelitian didapatkan bahwa dari 32 ibu yang berpartisipasi aktif dalam kelas ibu hamil sebanyak 17 ibu $(53,1 \%)$ ikutserta dalam kelas ibu hamil sebanyak 9 kali selama kehamilannya, sebanyak 9 ibu $(28,1 \%)$ ikutserta dalam kelas ibu hamil sebanyak 6 kali selama kehamilannya dan sebanyak 6 ibu $(18,7 \%)$ ikutserta dalam 
kelas ibu hamil sebanyak 2 kali selama kehamilannya. Sedangkan yang dikatakan berpartisi-pasi kurang apabila frekuensi ikutserta dalam kelas ibu hamil $<3$ kali selama kehamilannya. Hal ini belum meme-nuhi target dari Dinas Kesehatan Kota Medan bahwa setiap ibu diharapkan berpartisipasi aktif selama kehamilannya dalam kelas ibu hamil.

Berbeda dengan hasil penelitian Astuti menunjukkan keikutsertaan kelas ibu hamil di Wilayah Kerja Puskesmas Candiroto Kabupaten Temanggung kategori kurang aktif yaitu 37 orang $(72,5 \%)$. Hasil penelitian menunjukkan keikutsertaan kelas ibu hamil di Wilayah Kerja Puskesmas Candiroto Kabupaten Temanggung kategori aktif yaitu 14 orang $(27,5 \%)$. (Astuti et al., 2016)

Kelas ibu hamil merupakan kelompok belajar ibu-ibu hamil dengan umur kehamilan antara 4 minggu s/d 36 minggu (menjelang persalinan) dengan jumlah peserta maksimal 10 orang. Ibu-ibu hamil di kelas ini akan belajar bersama, diskusi dan tukar pengalaman tentang kesehatan Ibu dan anak (KIA) secara menyeluruh dan sistimatis serta dapat dilaksanakan secara terjadwal dan berkesinambungan. Kelas ibu hamil difasilitasi oleh bidan/tenaga kesehatan dengan menggunakan paket kelas ibu hamil yaitu buku KIA, flip chart (lembar balik), pedoman pelaksanaan kelas ibu hamil, pegangan fasilitator kelas ibu hamil dan buku senam ibu hamil (Kementrian Kesehatan RI, 2020).

Pendidikan dalam kelas ibu hamil (prenatal class) di negara asing menunjukkan hasil positif dan telah berkembang menjadi standar kelas promosi kesehatan di berbagai fasilitas kesehatan (Berman, 2006). Responden mempunyai keikutsertaan mengikuti kelas ibu hamil kategori kurang aktif salah satunya disebabkan oleh faktor pekerjaan. Tetapi diharapkan dengan mengikuti kelas ibu hamil, ibu hamil dapat meningkatkan pengetahuan, merubah sikap dan perilaku ibu agar memahami tentang kehamilan, perubahan tubuh dan keluhan selama kehamilan, perawatan kehamilan, persalinan, perawatan nifas, keluarga berencana pasca persalinan, penyakit menular dan akte kelahiran (Yusmaharani, 2019)

3. Hubungan Dukungan Keluarga Dengan Keikutsertaan Kelas Ibu Hamil Di Klinik Bidan Wanti

Berdasarkan penelitian didapatkan dari 59,4\% ibu hamil yang didukung keluarga untuk mengikuti kelas ibu hamil mayoritas ikut serta dalam kelas ibu hamil, dan 40,6\% ibu hamil yang tidak didukung oleh keluarga untuk ikut serta dalam kelas ibu hamil mayoritas tidak mengikuti kelas ibu hamil. Hasil uji statistik diperoleh nilai $p$ value 0,005 $(\alpha<0,05)$, yang berarti ada hubungan yang signifikan antara dukungan keluarga dengan keikutsertaan kelas ibu hamil di Klinik Bidan Wanti.

Sejalan dengan hasil penelitian penelitian E. Nugraheny\& Norhayati (2015); Astuti, et.al, (2016); Yusmaharani, (2019) hubungan dukungan keluarga/suami dengan partisipasi ibu hamil untuk mengikuti kelas ibu hamil didapatkan hasil terdapat hubungan yang secara statistik signifikan antara dukungan suami dan partisipasi ibu dalam mengikuti kelas ibu hamil. Ibu hamil yang didukung keluarga memiliki kemungkinan untuk mengikuti kelas ibu hamil 2,86 kali lebih besar daripada tidak didukung $(\mathrm{OR}=2,86 ; \mathrm{p}=0.002)$.

Keluarga adalah orang dianggap paling dekat oleh ibu, dan juga orang yang bertanggung jawab dalam, segala hal terhadap sesuatu tentang ibu. Keluarga mempunyai fungsi dukungan instrumental yaitu dukungan keluarga yang diberikan untuk memenuhi kebutuhan fisik ibu dengan bantuan keluarga, dukungan informasi yaitu dukungan 
keluarga dalam memberikan informasi yang diperolehnya mengenai kehamilan, dukungan penilaian yaitu memberikan keputusan yang tepat untuk perawatan kehamilan istrinya dukungan emosi yaitu suami sepenuhnya memberi dukungan secara psikologis kepada istrinya dengan menunjukkan kepedulian dan perhatian kepada kehamilannya serta peka terhadap kebutuhan dan perubahan emosi ibu hamil (Sudarmiati, 2013).

Hal ini berarti bahwa keluarga harus mencari informasi dan memberikan informasi tersebut kepada ibu terutama informasi mengenai partisipasi kelas ibu hamil. Keluarga juga perlu memberikan dukungan penghargaan pada ibu meliputi memberikan rasa aman, lingkungan kondusif sehingga membuat ibu semangat untuk berpartisipasi dalam kelas ibu hamil. Keluarga perlu meningkatkan dukungan emosional pada ibu yaitu dengan memberikan support/semangat melalui kalimat pujian atau kata-kata. Selain itu keluarga juga harus memberikan dukungan instrumental yaitu bantuan fisik kebutuhan Ibu (Wittmann-Price et al., 2019)

Dorongan dan dukungan keluarga terhadap ibu hamil untuk mengikuti kelas ibu hamil serta pemeriksaan kehamilan lainnya sangat diperlukan. Dukungan keluarga atau suami dapat diukur dengan melihat, mendukung atau tidaknya terhadap keikutsertaan ibu dalam kelas ibu hamil. Dukungan suami pada program kelas ibu hamil dapat dilihat dari keikutsertaan suami minimal 1 kali pertemuan di kelas ibu hamil (Kementrian Kesehatan RI, 2020)

Adanya dukungan dari keluarga berperan sangat besar dalam menentukan status kesehatan ibu. Keterlibatan anggota keluarga atau orang terdekat terutama pasangan/suami dapat membantu terjadinya perubahan untuk berperilaku dan juga meningkatkan kesadaran untuk berubah ke arah hidup sehat. Apabila dilihat dari informasi kesehatan lebih banyak diperoleh dari petugas kesehatan, keluarga dan masyarakat, namun pada bentuk-bentuk dukungan sosial lainnya suamilah yang paling berperan pada ibu hamil. Pentingnya peran keluarga pada ibu hamil tidak hanya sebagai pengambil keputusan, keluarga juga diharapkan selalu siaga dan selalu memberi perhatian terhadap kesehatan dan keselamatan ibu hamil. Dukungan suami sangat membantu dalam pembentukan perilaku kesehatan ibu karena ibu hamil akan cenderung menuruti apa yang disarankan oleh suaminya, sehingga dukungan sosial suami menjadi faktor yang besar hubungannya dengan partisipasi ibu dalam kelas ibu hamil (Ranita et al., 2016).

Menurut asumsi peneliti bahwa ibu hamil dengan dukungan keluarga yang tidak mendukung tetapi ikutserta dalam senam hamil itu dikarenakan ibu hamil mendapatkan informasi dari teman atau karabat ibu yang pernah mengikuti senam hamil sebelumnya, namun dalam penelitian ini masih ditemukan ibu hamil yang tidak ada dukungan tetapi tidak ikutserta dalam melakukan kegiatan senam hamil itu dikarenakan masih ada ibu yang kurang mendapatkan support dan dukungan emosional dari keluarga dikarenakan keluarga yang terlalu sibuk dengan pekerjaan sehingga tidak ada waktu untuk menemani ibu untuk melakukan kegiatan kelas ibu hamil. Sedangkan pada penelitian ini juga ditemukan ibu yang mendapat dukungan keluarga tetapi tidak ikutserta dalam kegiatan senam hamil itu dikarenakan ada ibu yang kurang mendapatkan dukungan emosional dari keluarga karena ada keluarga yang mengantarkan istrinya senam hamil tetapi tidak mau menemani pada saat kegiatan senam hamil berlangsung itu dikarenakan keluarga yang sibuk dengan pekerjaannya sehingga tidak mempunyai waktu untuk menemani ibu. 
Sedangkan dukungan dari keluarga itu sangat penting bagi ibu dalam kegiatan kelas ibu hamil.

\section{Kesimpulan}

Berdasarkan penelitian yang dilakukan peneliti untuk mencari hubungan dukungan keluarga dengan keikutsertaan kelas ibu hamil di Klinik Bidan Wanti, maka peneliti mengambil kesimpulan Dukungan keluarga pada ibu hamil di Klinik Bidan Wanti mayoritas mendukung. Keikutsertaan kelas ibu hamil di Klinik Bidan Wanti mayoritas mengikuti kelas ibu hamil. Terdapat hubungan yang signifikan antara dukungan keluarga dengan keikutsertaan kelas ibu hamil di Klinik Binda Wanti, dengan nilai $p$ value 0,005 $(\alpha<0,05)$.

\section{Referensi}

Astuti, W. W., Sofiyanti, I., \& Widyaningsih, A. (2016). Faktor-Faktor Yang Berhubungan Dengan Keikutsertaan Mengikuti Kelas Ibu Hamil Di Puskesmas Candiroto Kabupaten Temanggung. Rakernas AIPKEMA 2016 "Temu Ilmiah Hasil Penelitian Dan Pengabdian Masyarakat," 033, 19-29.

Kementrian Kesehatan RI. (2020). Buku KIA Kesehatan Ibu dan Anak: Bagian Ibu. Katalog Dalam Terbitan. Kementerian Kesehatan RI, 1-38. https://kesga.kemkes.go.id/assets/file/pedoman/BUKU KIA REVISI 2020 LENGKAP.pdf\%0Ahttps://kesga.kemkes.go.id/assets/file/pedoman/BUKU KIA TAHUN 2020 BAGIAN IBU.pdf

Masini, M. (2015). Pengaruh Gravida, Pekerjaan, Dukungan Suami, Dukungan Bidan/Tenaga Kesehatan Terhadap Partisipasi Ibu Dalam Kelas Ibu Hamil Di Kabupaten Magelang. Jurnal Kebidanan, 4(8), 37-44.

Prabhakara, G. (2010). Health Statistics (Health Information System). In Short Textbook of Preventive and Social Medicine. https://doi.org/10.5005/jp/books/11257_5

Ranita, B. A., Hardjanti, T. S., \& Hendri. (2016). PENGARUH BELLY DANCE TERHADAP TINGKAT KECEMASAN IBU HAMIL PRIMIGRAVIDA TRIMESTER III DI BPM RANTING 3 KoTA SEMARANG. In Jurnal Ilmiah Bidan: Vol. I (Issue 3).

Sawan, D. I., \& Buleleng, K. (2019). Jurnal Kesehatan MIDWINERSLION. 4(2), 101106.

Syam, A. Z., Suriah, \& Abdullah, M. T. (2018). Decision Making Behaviour By Pregnant Women in Searching for Health Services in Coastal Areas of Palu City Aswar Zulkifli Syam Program Pascasarjana.

Tarigan, P. B. (2013). Pengaruh Lingkungan Keluarga Terhadap Hasil Belajar Siswa Pada Mata Pelajaran Ekonomi Kelas Xi Ilmu Pengetahuan Sosial Sekolah Menengah Atas Al-Huda Pekanbaru. Journal of Chemical Information and Modeling, 53(9), 1689-1699. www.scholarshub.net

Uktutias, S. A. M., Pratiwi, N. L., \& Purnomo, W. (2018). Pengaruh Kesadaran Situasi Ibu Hamil Dengan Frekuensi Kunjungan Antenatal Di Wilayah Kerja Puskesmas Waru Kabupaten Pamekasan Tahun 2016. Buletin Penelitian Sistem Kesehatan, 21(1), 15-21. https://doi.org/10.22435/hsr.v21i1.89

Wittmann-Price, R. A., Wilson, L., \& Gittings, K. K. (2019). Kebidanan Komunitas. In 
JINTAN : Jurnal Ilmu Keperawatan

ISSN 2774-468X (Media Online)

Vol 1, No 2, Bulan Juli 2021

Hal 141-150

Certified Academic Clinical Nurse Educator (CNE ® cl) Review Manual.

Yusmaharani. (2019). HUBUNGAN DUKUNGAN SUAMI DENGAN

PEMANFAATAN KELAS IBU HAMIL. Kesmas Asclepius, 1, 86-95.

https://doi.org/https://doi.org/10.31539/jka.v1i2.586 